\title{
Difícil para unos, utópico para otros: la deficiente regulación de las prácticas formativas y su impacto negativo en las personas con discapacidad( ${ }^{*}\left({ }^{(* *}\right)\left(^{* * *}\right)\left(^{* * *}\right)$
}

\author{
Challenging for some, utopian for others: the poor regulation of training \\ practices and its negative impact on people with disabilities
}

\author{
Magda Cristina Verano Calero ${ }^{(* * * *)}$ \\ Pontificia Universidad Católica del Perú (Lima, Perú) \\ Astrid Carolina Flores Huamani $\left.{ }^{(* \star \star \star \star *}\right)$
Pontificia Universidad Católica del Perú (Lima, Perú) \\ Renato Antonio Constantino Caycho ${ }^{(* * * * * *)}$ \\ Pontificia Universidad Católica del Perú (Lima, Perú)
}

Resumen: La educación superior ha experimentado importantes cambios en los últimos años. Sin embargo, la deficiente regulación de las prácticas formativas se ha mantenido. El propósito de este artículo es analizar la regulación de las prácticas formativas, y su

$\left({ }^{*}\right) \quad$ Nota del Editor: este artículo fue recibido el 20 de agosto de 2020 y su publicación fue aprobada el 19 de octubre de 2020.

$\left({ }^{* *}\right) \quad$ Los autores agradecen a Saulo Galicia, María Alejandra Espino y Erick Beyá, quienes formularon comentarios y observaciones críticas a versiones anteriores de este trabajo

${ }^{* * *}$ El presente artículo se sustenta, por un lado, en la investigación "La formación práctica de las personas con discapacidad de la Facultad de Derecho PUCP" realizado por Cristina Verano y Antuanet Jiménez, con asesoría de Renato Constantino. El proyecto ganó el VII Concurso de Investigación Jurídica de Responsabilidad Social. Por otro lado, en la investigación "Trabas en el camino: la lucha de estudiantes con discapacidad por titularse" realizado por Cristina Verano, Astrid Flores, Antuanet Jiménez y Gabriela Poma, con asesoría de Renato Constantino. El proyecto ganó el 1er Fondo Concursable de Iniciativas de Investigación con enfoque de Responsabilidad Social Universitaria. Se hace extensivos los agradecimientos a la Facultad de Derecho de la PUCP y a la OARS por el financiamiento a la última investigación mencionada.

Las dos investigaciones antes mencionadas han cumplido con los protocolos del Comité de Ética de Investigación con Seres Humanos y Animales (CEISHA). Asimismo, todos los entrevistados dieron su consentimiento para realizar el presente artículo.

$\left({ }^{* * *}\right)$ Los autores creen en la igualdad de género y en la importancia que se refleje en el lenguaje. No obstante, para evitar la duplicidad de grafías y facilitar la lectura para las personas con discapacidad que usan lectores de pantalla, se ha optado por usar el plural con "o" para incorporar a hombres y mujeres.

$\left(^{* * * *}\right)$ Bachillera en Derecho por la Pontificia Universidad Católica del Perú. Miembro del Grupo Interdisciplinario de Investigación en Discapacidad de la PUCP-GRIDIS. Interés en temas de género y derechos de las personas con discapacidad. ORCID: 0000-00034683-9525. Correo electrónico: c.verano@pucp.pe

$\left(^{* * * * *}\right)$ Alumna del 11vo ciclo de pregrado en la Facultad de Derecho de la Pontificia Universidad Católica del Perú. Practicante en la Oficina de Prácticas Preprofesionales y SECIGRA Derecho PUCP. Miembro de la Clínica Jurídica de Derechos de las personas con discapacidad-PUCP. Interés en temas de derechos humanos, derechos de las personas con discapacidad y temas de derecho laboral. ORCID: 0000-0001-8397-7703. Correo electrónico: astrid.floresh@pucp.edu.pe

$\left.{ }^{(* * * * * *}\right)$ Docente del Departamento de Derecho de la Pontificia Universidad Católica del Perú. Abogado y magíster en Derechos Humanos por la misma casa de estudios. Cuenta con un LLM (Master of Laws) en International Legal Studies del Washington College of Law de American University. Investigador del Grupo Interdisciplinario en Discapacidad de la PUCP-GRIDIS. ORCID: 0000-00025721-1541. Correo electrónico: renato.constantino@pucp.pe 
falta de reconocimiento como trabajo bajo el marco jurídico vigente, situación que afecta desproporcionadamente a los estudiantes con discapacidad. Por último, se desarrolla un breve recuento de los principales hallazgos en entrevistas a estudiantes con discapacidad de la carrera de Derecho sobre esta materia.

Palabras Clave: Modalidades formativas - Discapacidad Educación superior -Prácticas preprofesionales - Prácticas profesionales

Abstract: In recent years higher education has undergone major changes. However, the poor regulation of training practices has remained. The purpose of this article is to analyze the regulation of training practices, and their lack of recognition as work under the current legal framework, a situation that disproportionately affects students with disabilities. Finally, a brief account is given of the main findings of interviews with law students with disabilities in this field.

Key Words: Training modalities - Disability - Higher education Pre-professional practices - Professional practices

\section{Introducción}

La educación superior ha experimentado importantes cambios en los últimos años en Perú. En gran medida, muchos de ellos responden a la promulgación de la Nueva Ley Universitaria que regula el marco normativo para la creación, aprobación o denegación del licenciamiento, el correcto funcionamiento, y la supervisión y promoción de la calidad de los servicios educativos de las universidades a cargo de la Superintendencia Nacional de Educación Superior Universitaria (en adelante SUNEDU) (Ley 30220, 2014, artículo 1). Producto de esta regulación, hasta la fecha, las universidades vienen atravesando un proceso de licenciamiento para brindar servicios educativos superiores de calidad.

Hasta agosto de 2020, 92 universidades- de las 141 existentes en Perú -cuentan con licenciamiento institucional y se ha denegado el licenciamiento a 47 universidades (Sunedu, 2020). De las universidades con licenciamiento, la región que presenta el mayor número de universidades licenciadas es Lima con un número ascendente a 37 . Lo anterior, refleja la centralización de la educación que se ha mantenido presente en los últimos años. Esta realidad afecta a todas las personas que reciben servicios educativos universitarios; sin embargo, para las personas con discapacidad las barreras se agudizan.

De acuerdo con el Perfil Sociodemográfico del Perú, "la población con discapacidad está conformada por 3,051,612 y representa el $10.4 \%$ del total de la población del país" (INEI, 2018, p. 177). En materia de educación, "el 13.9\% $(376,891)$ de personas con discapacidad de 15 y más años de edad no tiene nivel alguno de educación" (INEI, 2018, p. 193). Además, de acuerdo con el Ministerio de Educación, al 2017, 66 universidades de 117 encuestadas, tienen estudiantes con discapacidad; de las cuales, solo el $19 \%$ cuenta con procedimientos para la adaptación curricular, metodológica, de materiales y de evaluación para estudiantes con discapacidad (MINEDU, 2017). En esa misma línea, CONADIS reportó al 2018 que solo cuatro universidades son accesibles en cuanto a sus bibliotecas, auditorios, paraninfos, comedores, baños, ascensores, aulas, estacionamientos y espacios de circulación (CONADIS, 2018). Esta situación se debe a que las personas con discapacidad históricamente han sido excluidas del sistema educativo. Lo cual genera desigualdad no sólo en el derecho a la educación, sino también en otros derechos cuya condición para su ejercicio es la educación. Tal es el caso del derecho al trabajo, que se ve impedido considerablemente por la falta de educación de las personas con discapacidad.

En este contexto, el presente artículo busca presentar la realidad de las personas con discapacidad en la educación superior universitaria, específicamente en el acceso y ejercicio de las prácticas preprofesionales y profesionales. Para ello, abordaremos, primero, el marco normativo de las prácticas en el Perú con el objeto de identificar la naturaleza jurídica de las prácticas y los derechos de los practicantes. En el segundo segmento analizaremos las entrevistas trabajadas en un proyecto anterior que permiten conocer las percepciones de las personas con discapacidad sobre esta materia. Por último, sobre esa base, daremos un enfoque de discapacidad a la normativa de las prácticas. Así, identificaremos que las barreras legales que enfrentan las personas con discapacidad en el acceso y ejercicio a sus prácticas se deben en buena cuenta a la falta de reconocimiento de la modalidad formativa como relación laboral, aun cuando cumple con los elementos para serlo.

\section{Marco normativo de las prácticas en Perú}

Las personas con discapacidad enfrentan 
una serie de barreras para su inclusión educativa y laboral en Perú. En tal sentido, los efectos de la desprotección normativa general, impactan de manera más gravosa en esta población ${ }^{(1)}$. Así, la flexibilización de los derechos laborales a partir de la Constitución de 1993 tiene un efecto claro en las protecciones que pueden tener. La Constitución de 1993 eliminó varias de las protecciones establecidas en la Constitución de 1979, tales como: "La estabilidad laboral, la regulación del trabajo nocturno en condiciones peligrosas y la consagración de los derechos a compensación por tiempo de servicios, gratificaciones, bonificaciones y participación en la gestión y propiedad de la empresa" (Vidal, 2009, p. 174).

Dentro de esas desprotecciones, se crearon figuras jurídicas que, cumpliendo con los requisitos para constituir relaciones laborales, quedaron fuera de las protecciones: las prácticas preprofesionales y profesionales.

\subsection{Naturaleza jurídica de las prácticas}

Paralelamente a la educación universitaria y/o posterior a ella, se encuentran las prácticas preprofesionales y profesionales. Siendo estas una de las modalidades formativas, reconocidas por la normativa nacional, que armoniza tanto el aprendizaje teórico como el aprendizaje práctico del estudiante de educación superior mediante el desempeño de actividades de formación profesional.

De esta manera, el objetivo de las prácticas es el aprendizaje, y no la prestación laboral. "De ahí que, nuestra legislación niegue, en todos los supuestos, la presencia del vínculo laboral en las modalidades formativas" (Arce, 2007, p. 171). Como consecuencia de ello se generan las siguientes implicancias: (i) reducción de derechos, (ii) falta de representatividad sindical, (iii) detrimento en las condiciones laborales, (iv) eliminación de estabilidad laboral, (v) eliminación de CTS, (vi) eliminación de utilidades, (vii) eliminación de asignación familiar, (viii) eliminación de indemnización por despido, entre otras. Bajo este enfoque, el ordenamiento jurídico solo se ha dirigido a crear relación precaria.

Por ello, diversos autores han señalado que esta calificación jurídica no es adecuada, pues en ciertos casos la real naturaleza de las prácticas es laboral(2). Ello es así cuando el practicante empieza a generar ganancias al centro de prácticas sin necesidad de un tutor que lo oriente a cumplir el plan de aprendizaje. Piénsese en un practicante que llega a un centro de prácticas con experiencia y al cabo de 6 meses maneja muy bien todas sus funciones. Esta es una situación común en las prácticas, puesto que "asumir que el único objetivo de un convenio de formación laboral es la capacitación, implica asumir que el empresario solo tiene un fin formativo; lo cual es falso" (Arce, 2007, pp. 171-172). Por ejemplo, en los artículos 1, 10 y el Título III de la Ley de Productividad y Competitividad Laboral se evidencia que la capacitación y la formación laboral son concebidas como un mecanismo de mejora para la productividad del trabajador (Decreto Supremo 003-97-TR, 1997, artículo 1 y 10). Entonces, ¿qué tanta diferencia existe entre la capacitación del practicante con el del trabajador? Realmente, no hay grandes diferencias.

Bajo un marco de reflexión, el estudiante o egresado libremente pone en práctica, a través de su fuerza de trabajo productivo, los conocimientos adquiridos en su Centro de Formación Profesional. Sin embargo, llega un punto en que es innegable reconocer que los practicantes producen ganancias a su Centro de Prácticas a partir de las actividades que realizan: elaboración de gestiones administrativas, informes en general, seguimiento de procedimientos administrativos o judiciales, efectuar registro de facturas de los proveedores, etc.

Siendo ello así, la norma no refleja la realidad de las prácticas, pues se concentra en el trabajo efectivo y la producción de patrimonio antes que la formación del practicante. En esa línea, "si bien las modalidades formativas que generen utilidad empresarial no pueden dar

(1) Al respecto, por ejemplo, dado que, en el Perú, el acceso a la seguridad social está vinculado con tener un empleo, la flexibilización de las normas laborales impacta particularmente en las personas con discapacidad pues, usualmente, pueden requerir mayores atenciones de salud.

(2) Véase:

Arce, E. (2007). Naturaleza Jurídica de las modalidades formativas laborales en la empresa. Foro Jurídico, núm. 7, pág. 172.

Fernández, C. (2015). La delgada línea entre lo laboral y lo formativo: las prácticas preprofesionales y profesionales. Actualidad Empresarial, núm. 336, p. 4.

Alonso, M., \& Casas, M. (2008). Derecho del Trabajo, p. 694.

Toyama, J. (2008). Modalidades formativas: capacitación y prácticas. Gaceta Jurídica, p. 97.

Boza, G. (1992). Convenios de formación laboral juvenil y de prácticas: ¿capacitación para el empleo o precarización del mismo? 
Difícil para unos, utópico para otros: la deficiente regulación de las prácticas formativas y su impacto negativo en las personas con discapacidad

Challenging for some, utopian for others: the poor regulation of training practices and its negative impact on people with disabilities

lugar a contratos de trabajo típicos, sí podría aceptarse que generen contratos de trabajo especiales"' (Arce, 2007, p. 172).

Para determinar que las prácticas cumplen con una naturaleza laboral es necesario examinar el cumplimiento de sus tres elementos: prestación personal, subordinación y remuneración. Por prestación personal se entiende que «la actividad cuya utilización es objeto del contrato de trabajo, es la específica de un trabajador determinado» (Neves, 2012, p. 24). En otras palabras, el trabajador, siendo una persona natural, a través de una relación personalísima presta su fuerza de trabajo. Pues bien, en el ejercicio de las prácticas, se cumple con este elemento, ya que el trabajador sería el practicante que cursa sus ciclos de la carrera profesional o ya los ha finalizado y cuenta con el grado académico de bachiller. Siendo el mismo practicante quien ofrece la fuerza de trabajo y quien los presta. En palabras sencillas, el practicante contratado es el mismo que realiza las funciones encomendadas.

Por otro lado, el segundo elemento, la subordinación, se refiere al "vínculo jurídico entre el trabajador y el empleador, en virtud del cual el primero le ofrece su actividad al segundo y le confiere el poder de conducirla" (Neves, 2012, p. 25). Es decir, por un lado, existirá sujeción, y, por otro, dirección. Este elemento también se cumple en el ejercicio de las prácticas, pues debido a la posición en la que se encuentra un practicante en la entidad privada o entidad estatal, siempre cuenta con una persona que lo dirige y coloca en un estado de sujeción. Siendo el empleador el que tenga la facultad organizativa, fiscalizadora y de sanción. En tanto, el practicante no cuenta con personas a su cargo, ya que se encuentra en un rango inferior en la jerarquía de organización de la entidad. Vale aclarar que la subordinación no es equivalente a maltratos, humillaciones o algún acto que vulnere los derechos de los practicantes. En nuestra opinión, el carácter formativo y de capacitación no anula el elemento de subordinación. Al respecto, la propia legislación en materia de prácticas establece características de la subordinación a la relación.

Finalmente, el tercer elemento es la remuneración. Tal aspecto del trabajo se presenta en los trabajos productivos por cuenta ajena, "donde el deudor ofrece su trabajo a un tercero, quien es el titular de lo que éste produce a cambio del pago de una retribución" (Neves, 2012, p. 28). Esta característica también se presenta en el caso de las prácticas, ya que mensualmente los practicantes, en la misma fecha en que se paga a los demás trabajadores, reciben una subvención que no puede ser menor a la remuneración mínima vital. La excepción a esta regla se da cuando el practicante cumple una jornada inferior a la de seis horas diarias o a la de treinta horas semanales. En estos casos el pago es proporcional.

En ese sentido, las prácticas califican como una relación laboral, pero el marco normativo ha decidido excluirlas de esa calificación con evidentes efectos negativos en los derechos de los practicantes. Sin embargo, la noción de que las prácticas son trabajo ha sido respaldada por el Comité de Libertad Sindical de la Organización Internacional del Trabajo(3) al analizar si los practicantes tienen derecho a organizarse colectivamente (Constantino \& Galicia, 2015, p. 272). A ello se añade que a los practicantes se les reconoce similares derechos que a los trabajadores, los cuales, curiosamente, deben ser interpretados de conformidad con los Convenios de la OIT (Ley 28518, 2005, Disposición complementaria primera).

\subsection{Los derechos de los practicantes}

Aun cuando las prácticas, en los hechos, son una relación laboral, no son asumidas bajo esta categoría por el ordenamiento jurídico peruano(4). "Esta desprotección provoca que los practicantes no puedan acceder a beneficios sociales legales propios de una relación laboral, como la compensación por tiempo de servicios, la participación de utilidades, entre otros" (Toyama, 2008, p. 104). De igual manera, los practicantes no gozan de estabilidad laboral, es decir, de protección contra la extinción unilateral del convenio de prácticas.

Además, se incumple con el derecho a la igualdad ante la ley, el cual consiste en que la ley debe operar para todos por igual cuando las personas se encuentren en la misma situación descrita por la norma. Así, los practicantes no pueden exigir el cumplimiento del derecho de igualdad ante la ley para alegar el otorgamiento de un beneficio o condición de trabajo percibido por

Asesoría Laboral, p. 13 y p.14.

(3) Véase Organización Internacional del Trabajo. (1996). Informe provisional - Informe núm. 304, Junio 1996. Caso núm. 1796 (Perú). https://www.ilo.org/dyn/normlex/es/f?p=NORMLEXPUB:50002:0::NO::P50002_COMPLAINT_TEXT_ID:2903259

(4) En la antigua Ley de Fomento del Empleo, aprobada por Decreto Legislativo 728 en 1991, tampoco se reconoció las prácticas como 
los trabajadores, pues no existe reconocimiento normativo de estos derechos para ellos.

De hecho, la legislación vigente no provee una regulación efectiva sobre la formación y capacitación del practicante: no existe fiscalización en el cumplimiento del plan de aprendizaje del practicante, no existen lineamientos para determinar el contenido de la capacitación (lo que genera la flexibilidad de este contenido) y no existen sanciones para los casos de deficiente formación profesional. Incluso, algunas entidades públicas se niegan a presentar al centro de formación profesional un plan de aprendizaje, ya que la legislación no los obliga. En otros casos, es materialmente imposible que el centro de formación profesional realice supervisión a todos los practicantes.

Bajo este contexto, las personas con discapacidad se ven expuestas a una situación de mayor vulnerabilidad. Pues no sólo deben enfrentar las barreras arquitectónicas, legales, sociales, etc. impuestas, sino también su falta de inclusión en las prácticas formativas. Para poder verificar esto adecuadamente, se hará un rápido recuento histórico de las prácticas para luego revisar el marco normativo actual referente a las prácticas.

En un primer momento, las prácticas en el sector público y privado se encontraban reguladas por la Ley de Fomento del Empleo (Decreto Legislativo 728, 1991). En un segundo momento, las prácticas fueron reguladas sólo bajo la aplicación de la Ley de Formación y Promoción Laboral. Luego, fueron reguladas con la Ley sobre modalidades formativas laborales (Ley 28518, 2005) y su reglamento (Decreto Supremo 0072005-TR, 2005). Aun publicado el Decreto Legislativo que aprueba el régimen especial que regula las modalidades formativas de servicios en el sector público (Decreto Legislativo 1401, 2018) se inaplicaba por la falta de su reglamento. En un cuarto momento, con la promulgación del reglamento del Decreto Legislativo 1401 (Decreto Supremo 083-2019-PCM, 2019) la Ley 28518 paso a regir únicamente en las prácticas del ámbito privado.

Se hace la acotación que el régimen del Programa Servicio Civil de Graduandos SECIGRA DERECHO (en adelante SECIGRA) se rigen por sus leyes especiales. Como veremos a continuación, son múltiples las diferencias entre las prácticas preprofesionales y profesionales, sea que se realice en el sector público o privado:

Para el análisis de los derechos, se tomarán como referencia los elementos resaltados en la tabla: ámbito de aplicación, perfil del practicante, duración del convenio, monto de la subvención, descanso subvencionado, jornada semanal, subvención adicional, seguro de salud y descuentos y aportes.

Con respecto al ámbito de aplicación, en el sector público, las prácticas se realizan en Entidades Públicas. Por el contrario, en el sector privado, las prácticas se realizan en empresas del régimen privado y en empresas públicas del Estado (Decreto Legislativo 1401, 2018, artículo 2; Ley 28518 , 2005, artículo III). Por ejemplo, Banco de la Nación, Petroperú, Sima Perú, entre otras.

Por otro lado, para los estudiantes de la Facultad de Derecho de las universidades peruanas, también existe la opción de realizar prácticas preprofesionales en el ámbito público mediante SECIGRA. Dicha modalidad se encuentra regulada bajo el Decreto Ley 26113 y el Decreto Supremo 009-2014-JUS. Asimismo, está a cargo del Ministerio de Justicia y Derechos Humanos, quien, en coordinación con las universidades, se encarga que los estudiantes realicen una experiencia formativa de un año en diversas entidades públicas, también conocidas como Unidades Receptoras. El proceso de preinscripción e inscripción lo realiza la Oficina de Prácticas Preprofesionales y SECIGRA entre los meses de noviembre y diciembre. Así, mediante acto público, el estudiante con mejor rendimiento académico tiene la posibilidad de elegir entre todas las vacantes que dan las entidades públicas. Sucesivamente, cada estudiante elegirá una entidad hasta que se acaben todas las vacantes.

Para los profesionales de la Ciencias de la Salud, titulados o colegiados, se presenta el SERUMS como requisito indispensable para poder trabajar en el sector público. Este programa se encuentra regulado por la Ley 23330 y el Decreto Supremo 005-97SA. Se lleva a cabo en puestos, centros de salud, hospitales de apoyo e instituciones no públicas, los cuales se encuentran ubicados en zonas rurales y urbanas de menor desarrollo en Perú. Asimismo, en el caso de profesionales de medicina humana existe el SINAREME. Este programa se encuentra regulado por la Ley 30453 y el Decreto Supremo 007-2017-SA. Básicamente, este programa se realiza en las instituciones prestadoras de servicios de salud acreditadas por CONAREME.

Con respecto al perfil del practicante, el acceso a las prácticas preprofesionales en el sector privado es para el general de los estudiantes (Ley 28518, 2005, artículo 12). En cambio, en el sector público solo acceden 
Difícil para unos, utópico para otros: la deficiente regulación de las prácticas formativas y su impacto negativo en las personas con discapacidad

Challenging for some, utopian for others: the poor regulation of training practices and its negative impact on people with disabilities

\begin{tabular}{|c|c|c|c|}
\hline $\begin{array}{c}\text { Primer momento } \\
\text { (1991-1996) }\end{array}$ & $\begin{array}{c}\text { Segundo momento } \\
(1997-2005)\end{array}$ & $\begin{array}{c}\text { Tercer momento } \\
\text { (2005/2018-actualmente) }\end{array}$ & $\begin{array}{l}\text { Cuarto momento } \\
\text { (2019-actualmente) }\end{array}$ \\
\hline $\begin{array}{l}\text { Las prácticas del sector público } \\
\text { y privado se regulaban por } \\
\text { el Capítulo II y III del Título I } \\
\text { denominado "De la Capacitación } \\
\text { para el trabajo", de la Ley de } \\
\text { Fomento del Empleo (Decreto } \\
\text { Legislativo 728, 1991). }\end{array}$ & $\begin{array}{l}\text { Las prácticas del sector público y privado } \\
\text { pasan a regir por la Ley de Formación y } \\
\text { Promoción Laboral. } \\
\text { Mediante la Disposición Transitoria del } \\
\text { Decreto Legislativo N }{ }^{\circ} 855 \text { se divide la Ley } \\
\text { de Fomento del Empleo en } 2 \text { normas: (i) Ley } \\
\text { de Formación y Promoción Laboral y (ii) Ley } \\
\text { de Productividad y Competitividad Laboral } \\
\text { (Decreto Legislativo 855, 1996). }\end{array}$ & $\begin{array}{l}\text { A partir de } 2005 \text {, las prácticas del } \\
\text { sector público y privado se regulan } \\
\text { por la Ley sobre modalidades } \\
\text { formativas laborales y su } \\
\text { reglamento. } \\
\text { Luego de } 13 \text { años, en } 2018 \text {, se } \\
\text { publica la norma que regula las } \\
\text { prácticas en el sector público (más } \\
\text { no su reglamento). }\end{array}$ & $\begin{array}{l}\text { Se publica el Reglamento del } \\
\text { Decreto Legislativo } 1401 \text {. } \\
\text { Las prácticas empiezan a } \\
\text { regularse normativamente por el } \\
\text { sector al que pertenezcan: público } \\
\text { o privado. }\end{array}$ \\
\hline
\end{tabular}

Elaboración propia.

Tabla 1: Diferencias entre el régimen de prácticas preprofesionales del sector público y privado

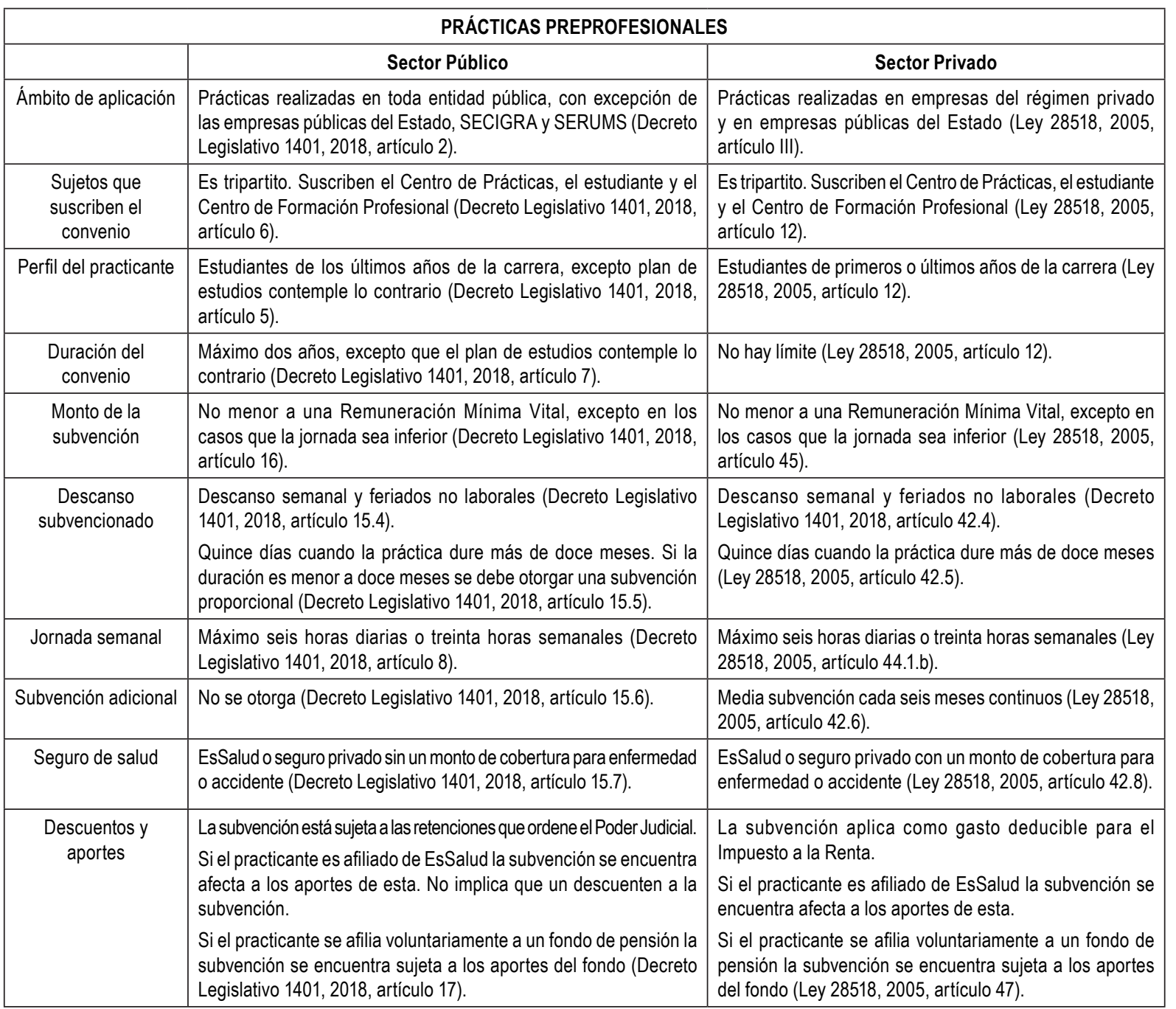

Elaboración propia. 
Tabla 2: Diferencias entre el régimen de prácticas profesionales en el sector público y privado

\begin{tabular}{|c|c|c|}
\hline \multicolumn{3}{|c|}{ PRÁCTICAS PROFESIONALES } \\
\hline & Sector Público & Sector Privado \\
\hline Ámbito de aplicación & $\begin{array}{l}\text { Prácticas realizadas en toda entidad pública, con excepción de } \\
\text { las empresas públicas del Estado, SECIGRA y SERUMS (Decreto } \\
\text { Legislativo 1401, 2018, artículo 2). }\end{array}$ & $\begin{array}{l}\text { Prácticas realizadas en empresas del régimen privado } \\
\text { y en empresas públicas del Estado (Ley 28518, 2005, } \\
\text { artículo III). }\end{array}$ \\
\hline $\begin{array}{l}\text { Sujetos que } \\
\text { suscriben el convenio }\end{array}$ & $\begin{array}{l}\text { Es bipartito. Suscribe el Centro de Prácticas y el estudiante } \\
\text { (Decreto Legislativo 1401, 2018, artículo 11). }\end{array}$ & $\begin{array}{l}\text { Es bipartito. Suscribe el Centro de Prácticas y el estudiante } \\
\text { (Ley 28518, 2005, artículo 13). }\end{array}$ \\
\hline Perfil del practicante & Egresado universitario (Decreto Legislativo 1401, 2018, artículo 10) & Egresado universitario (Ley 28518, 2005, artículo 13). \\
\hline $\begin{array}{l}\text { Duración del } \\
\text { convenio }\end{array}$ & $\begin{array}{l}\text { Máximo doce meses desde el cambio de la condición de estudiante } \\
\text { a egresado (Decreto Legislativo 1401, 2018, artículo 12) }\end{array}$ & $\begin{array}{l}\text { Máximo doce meses, salvo la normativa interna del } \\
\text { centro de estudios indique lo contrario (Ley 28518, 2005, } \\
\text { artículo 13). }\end{array}$ \\
\hline $\begin{array}{l}\text { Monto de la } \\
\text { subvención }\end{array}$ & $\begin{array}{l}\text { No menor a una Remuneración Mínima Vital, excepto en los } \\
\text { casos que la jornada sea inferior (Decreto Legislativo 1401, 2018, } \\
\text { artículo 16). }\end{array}$ & $\begin{array}{l}\text { No menor a una Remuneración Mínima Vital, excepto en } \\
\text { los casos que la jornada sea inferior (Ley 28518, 2005, } \\
\text { artículo 45). }\end{array}$ \\
\hline \multirow{2}{*}{$\begin{array}{l}\text { Descanso } \\
\text { subvencionado }\end{array}$} & $\begin{array}{l}\text { Descanso semanal y feriados no laborales (Decreto Legislativo } \\
\text { 1401, 2018, artículo 15.4). }\end{array}$ & $\begin{array}{l}\text { Descanso semanal y feriados no laborales (Decreto } \\
\text { Legislativo 1401, 2018, artículo 42.4). }\end{array}$ \\
\hline & $\begin{array}{l}\text { Quince días cuando la práctica dure más de doce meses. Si la } \\
\text { duración es menor a doce meses, se debe otorgar una subvención } \\
\text { proporcional (Decreto Legislativo 1401, 2018, artículo 15.5). }\end{array}$ & $\begin{array}{l}\text { Quince días cuando la práctica dure más de doce meses } \\
\text { (Ley 28518, 2005, artículo 42.5). }\end{array}$ \\
\hline Jornada semanal & $\begin{array}{l}\text { Máximo ocho horas diarias o cuarenta y ocho horas semanales } \\
\text { (Decreto Legislativo 1401, 2018, artículo 13). }\end{array}$ & $\begin{array}{l}\text { Máximo ocho horas diarias o cuarenta y ocho horas } \\
\text { semanales (Ley } 28518,2005 \text {, artículo } 44.2 \text { ). }\end{array}$ \\
\hline Subvención adicional & $\begin{array}{l}\text { Media subvención cada seis meses continuos (Decreto Legislativo } \\
\text { 1401, 2018, artículo 15.6). }\end{array}$ & $\begin{array}{l}\text { Media subvención cada seis meses continuos (Ley } 28518 \text {, } \\
\text { 2005, artículo 42.6). }\end{array}$ \\
\hline Seguro de salud & $\begin{array}{l}\text { EsSalud o seguro privado sin un monto de cobertura para } \\
\text { enfermedad o accidente (Decreto Legislativo 1401, 2018, artículo } \\
\text { 15.7). }\end{array}$ & $\begin{array}{l}\text { EsSalud o seguro privado con un monto de cobertura para } \\
\text { enfermedad o accidente (Ley 28518, 2005, artículo 42.8). }\end{array}$ \\
\hline \multirow{3}{*}{ Descuentos y aportes } & \multirow{3}{*}{$\begin{array}{l}\text { La subvención está sujeta a las retenciones que ordene el Poder } \\
\text { Judicial. } \\
\text { Si el practicante es afiliado de EsSalud la subvención se encuentra } \\
\text { afecta a los aportes de esta. No implica que un descuenten a la } \\
\text { subvención. } \\
\text { Si el practicante se afilia voluntariamente a un fondo de pensión la } \\
\text { subvención se encuentra sujeta a los aportes del fondo (Decreto } \\
\text { Legislativo } 1401,2018 \text {, artículo 17). }\end{array}$} & $\begin{array}{l}\text { La subvención aplica como gasto deducible para el } \\
\text { Impuesto a la Renta. }\end{array}$ \\
\hline & & $\begin{array}{l}\text { Si el practicante es afiliado de EsSalud la subvención se } \\
\text { encuentra afecta a los aportes de esta. }\end{array}$ \\
\hline & & $\begin{array}{l}\text { Si el practicante se afilia voluntariamente a un fondo de } \\
\text { pensión la subvención se encuentra sujeta a los aportes } \\
\text { del fondo (Ley 28518, 2005, artículo 47). }\end{array}$ \\
\hline
\end{tabular}

Elaboración propia.

los estudiantes de los últimos años de la carrera, excepto plan de estudios del Centro de Formación contemple lo contrario (Decreto Legislativo 1401, 2018, artículo 5). Caso similar es en SECIGRA, ya que está dirigido para estudiantes que cursen el último año de estudios. Por otro lado, en las prácticas profesionales, tanto en el sector privado como público, acceden los egresados antes de la obtención del título profesional.

En lo referente al monto de la subvención, tanto en las prácticas preprofesionales y profesionales, esta no puede ser menor a una Remuneración Mínima Vital cuando el practicante preprofesional cumpla 30 horas semanales o el practicante profesional cumpla 48 horas semanales (Decreto Legislativo 1401, 2018, artículo 7; Ley 28518, 2005, artículo 45). Puede darse el caso que el practicante cumpla una jornada inferior. En estos casos el pago debe ser proporcional. Sin embargo, consideramos antiético que un empleador pacte 28 horas de prácticas y pague proporcionalmente bajo este número de horas. Ello en la medida que lo más probable es que esas 2 horas al final 
Difícil para unos, utópico para otros: la deficiente regulación de las prácticas formativas y su impacto negativo en las personas con discapacidad

Challenging for some, utopian for others: the poor regulation of training practices and its negative impact on people with disabilities

sean ejecutadas por el practicante y no se les pague por ello. Caso contrario es cuando el empleador acuerda una subvención superior. Por ejemplo, algunos estudios de abogados pactan con el practicante una jornada de 25 horas, pero les pagan por encima de la Remuneración Mínima Vital. Se sigue la misma línea en SECIGRA solo que se le denomina estipendio y este no puede ser superior o inferior a una Remuneración Mínima Vital.

Si bien la remuneración mínima ha ido aumentando en beneficio de los practicantes, debe tomarse en cuenta que en el caso de las personas con discapacidad este monto resulta insuficiente por los gastos en que incurren. Por ejemplo, movilidad segura, citas médicas, hojas braille, etc.

En lo referente al descanso subvencionado, en el ámbito público y privado, cuando el practicante preprofesional o profesional cumplan más de doce meses se hace acreedor de 15 días de descanso debidamente subvencionado (Decreto Legislativo 1401, 2018, artículo 15; Ley 28518, 2005, artículo 42). El pago de este periodo de descanso debe ser realizado antes del mismo. Cabe señalar que los periodos intermitentes se acumulan a favor del practicante. Asimismo, el derecho subsiste en caso: (i) el convenio o prórroga de este finalice después de haber cumplido 12 meses y (ii) no se haya disfrutado del descanso. Así, el empleador tiene la obligación de pagar los 15 días al practicante.

Aparte de lo ya mencionado, en el ámbito público se da un beneficio extra al practicante: cuando la duración es menor de 12 meses igual se da una subvención económica proporcional, la cual debe ser otorgado al mes siguiente. Es decir, el practicante del ámbito público siempre será beneficiado en lo referente al descanso subvencionado.

En el caso de los secigristas, estos gozan de dos semanas de receso en el mes de julio; sin embargo, dicho periodo de tiempo puede ser intercambiado por el secigrista únicamente para rendir exámenes, parciales y finales, previa aceptación por parte de la Unidad Receptora.

Sobre el máximo de la jornada laboral, el número máximo de horas para las prácticas preprofesionales, tanto para el ámbito público y privado, y SECIGRA es de 6 horas diarias o 30 horas semanales (Decreto Legislativo 1401, 2018, artículo 8; Ley 28518, 2005, artículo 44). En el caso de prácticas profesionales, sea en el ámbito público o privado, el número máximo es de 8 horas diarias o 48 horas semanales (Decreto Legislativo 1401, 2018, artículo 13; Ley 28518, 2005, artículo 44). Cabe mencionar que el Decreto Supremo 003-2008TR dicta medidas sobre jornadas máximas de modalidades formativas en la carrera de Derecho y de internado en Ciencias de la Salud. Lo anterior, crea un trato desigual a las demás profesiones. Así, solo los practicantes de Derecho y de internado en Ciencias de la Salud son favorecidos por la aplicación del Principio de Primacía de la Realidad y una sanción pecuniaria (Decreto Supremo 0032008-TR, 2008, artículo 2 y artículo 3).

Sobre la subvención adicional, tanto en las prácticas preprofesionales como profesionales, sea del ámbito privado o público, se reconoce la mitad de una subvención al cumplir seis meses de prácticas. Cabe señalar que los periodos intermitentes se acumulan a favor del practicante (Decreto Legislativo 1401, 2018, artículo 15; Ley 28518, 2005, artículo 42).

Sobre el seguro de salud, en el ámbito privado «se cubre los riesgos de enfermedad y accidente a través de EsSalud o de un seguro privado con una cobertura de catorce subvenciones mensuales en caso de enfermedad y treinta por accidente» (Ley 28518, 2005, artículo 42). En cambio, en el ámbito público, no se establece a cuánto equivaldrá la cobertura de salud y accidente (Decreto Legislativo 1401, 2018, artículo 15).

Es importante resaltar que el seguro médico para las personas con discapacidad es una medida de suma relevancia. Así, las personas con discapacidad determinan su decisión entre unas prácticas en el sector privado o público por esta materia, ya que en el sector público EsSalud no tiene un límite de cobertura.

Bajo este contexto normativo, como se ha señalado, la falta de derechos genera una situación de mayor indefensión hacia los practicantes con discapacidad, como se puede observar en la siguiente tabla 3.

\section{Percepciones en discapacidad sobre las prácticas de derecho}

A fin de visibilizar la percepción de los estudiantes con discapacidad en el acceso y ejercicio de las prácticas formativas, a continuación, desarrollaremos un breve recuento de los principales hallazgos del

\footnotetext{
(5) Proyecto ejecutado por Cristina Verano, Astrid Flores, Antuanet Jiménez y Gabriela Poma, durante el periodo de mayo del 2018 a junio del 2019, y con financiamiento de la Oficina de Responsabilidad Social Universitaria de la Facultad de Derecho de la PUCP.
} 
Tabla 3: Diferencias entre un practicante con discapacidad y un practicante sin discapacidad

\begin{tabular}{|l|l|l|}
\hline \multicolumn{3}{|c|}{ PRÁCTICAS PROFESIONALES Y PREPROFESIONALES } \\
\hline & \multicolumn{1}{|c|}{ Practicante con discapacidad } & \multicolumn{1}{c|}{ Practicante sin discapacidad } \\
\hline $\begin{array}{l}\text { Ámbito de } \\
\text { aplicación } \\
\text { público o privado) }\end{array}$ & $\begin{array}{l}\text { Elegiria teniendo en cuenta qué ámbito ofrece mayores facilidades, } \\
\text { flexibilidad, implementación de ajustes razonables, etc. } \\
\text { Deja en segundo plano sus áreas de interés. }\end{array}$ & $\begin{array}{l}\text { Elegiría de forma libre y sin mayores preocupaciones, } \\
\text { priorizando sus áreas de interés. }\end{array}$ \\
\hline $\begin{array}{l}\text { Perfil del } \\
\text { practicante }\end{array}$ & $\begin{array}{l}\text { Alta probabilidad que realice SECIGRA o prácticas profesionales } \\
\text { para cumplir el requisito para la obtención del título profesional. }\end{array}$ & $\begin{array}{l}\text { Alta probabilidad que realice prácticas preprofesionales y } \\
\text { cumpla sin problema el requisito para la obtención del título } \\
\text { profesional. }\end{array}$ \\
\hline $\begin{array}{l}\text { Monto de la } \\
\text { subvención }\end{array}$ & $\begin{array}{l}\text { La RMV le resulta insuficiente por los costos de los ajustes razonables } \\
\text { que tiene que asumir para ejercer las prácticas en igualdad de } \\
\text { condiciones. }\end{array}$ & $\begin{array}{l}\text { No realiza gastos para implementar ajustes razonables. } \\
\text { Tendrá mayor liquidez. }\end{array}$ \\
\hline Jornada semanal & $\begin{array}{l}\text { Mayor dificultad de compatibilizar horas de estudio con las horas } \\
\text { de prácticas. }\end{array}$ & $\begin{array}{l}\text { Menor dificultad de compatibilizar horas de estudio con las } \\
\text { horas de prácticas. }\end{array}$ \\
\hline Seguro de salud & $\begin{array}{l}\text { Alta importancia en la elección del seguro de salud. } \\
\text { Preferirá el seguro de EsSalud, ya que su cobertura es mayor. }\end{array}$ & Baja importancia en la elección del seguro de salud. \\
\hline
\end{tabular}

Elaboración propia.

proyecto "Trabas en el camino: la lucha de estudiantes con discapacidad por titularse"(5), investigación de tipo cuantitativa y cualitativa ejecutada entre el 2018 y 2019 a estudiantes de la carrera de Derecho. El método de recolección de datos fue mediante entrevistas presenciales y virtuales a seis estudiantes con discapacidad(6): cuatro estudiantes de la Facultad de Derecho de la PUCP y dos estudiantes de la Facultad de Derecho y Ciencia Política de la Universidad Nacional Mayor de San Marcos (en adelante, UNMSM). Se eligió a estas dos universidades debido a que: a) son las Facultades de Derecho privada y pública más antiguas del país, respectivamente; b) había certeza plena de la existencia de estudiantes con discapacidad; y c) se contaba con informantes (formales e informales) que permitían la identificación de todos los estudiantes con discapacidad y no solamente una muestra. Se entrevistó a esta cantidad tan reducida de personas pues el número de estudiantes con discapacidad de la Facultad de Derecho de cada universidad es bajo(7). A pesar de que se intentó convocar a la totalidad de estudiantes con discapacidad, solo en el caso de la PUCP se pudo conseguir este objetivo; en el caso de la UNMSM, tres personas desistieron de participar en la investigación.

En la investigación se buscó identificar si los estudiantes con discapacidad contaban o no con una protección adecuada de derechos en el ámbito de modalidades formativas ${ }^{(8)}$. A pesar de que la experiencia de las prácticas preprofesionales y profesionales para estudiantes con discapacidad varía de acuerdo a la etapa del proceso en la que se encuentren, los resultados de las entrevistas nos permitieron comprobar que, efectivamente, los estudiantes con discapacidad no cuentan con dicha protección. Esta situación se explica con el hecho de que los estudiantes con discapacidad enfrentan múltiples barreras en el acceso, ejercicio y obtención de resultados de sus prácticas preprofesionales y profesionales, que les impiden obtener el grado de titulado en

Lainvestigación eumpliócen los protocolos del Comité de Ética de Investigación con Seres Humanos y Animales (CEISHA).

(6) Todos los entrevistados dieron su consentimiento para realizar el presente artículo.

(7) En el caso de la Facultad de Derecho de la PUCP, la cifra total de estudiantes con discapacidad vigentes al momento de la investigación fue proporcionada por la Secretaría Académica de la Facultad para efectos de la investigación. Distinto fue el caso de la Oficina de Prácticas de la Facultad de Derecho de la UNMSM, que manifestó no contar con esa información.

(8) Las preguntas de la investigación fueron: “¿fue difícil para los estudiantes con discapacidad encontrar prácticas preprofesionales o profesionales?, ¿los estudiantes con discapacidad recibieron comentarios negativos o prejuiciosos solo por tener discapacidad?, ¿los estudiantes con discapacidad tuvieron o no medidas de apoyo para realizar sus prácticas?, ¿alguna autoridad de la universidad se acercó al centro de prácticas para corroborar el trato que recibía el/la estudiante con discapacidad?, ¿las organizaciones no gubernamentales manejan la problemática de los estudiantes con discapacidad en la búsqueda, ejercicio de prácticas y la inserción 
Difícil para unos, utópico para otros: la deficiente regulación de las prácticas formativas y su impacto negativo en las personas con discapacidad

Challenging for some, utopian for others: the poor regulation of training practices and its negative impact on people with disabilities

igualdad de condiciones.

\subsection{Sobre las barreras en el acceso a las prácticas}

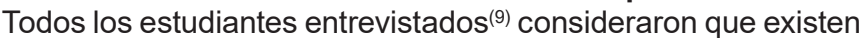
dificultades para acceder a prácticas preprofesionales. Sin embargo, la explicación de las causas varió de acuerdo a sus propias experiencias. Así, la mitad de las personas entrevistadas ${ }^{(10)}$ consideró que existen dos motivos fundamentales que dificultan el acceso a las prácticas: las aptitudes académicas y la falta de experiencia previa. En ese sentido, consideraron que la barrera es la exigencia de ciertos requisitos en los centros de prácticas, tales como: cursar un año o ciclo determinado en la universidad, o, contar con estudios de inglés. De acuerdo con los entrevistados, estos aspectos son complicados de alcanzar por las personas con discapacidad ${ }^{(11)}$. En primer lugar, el cumplimiento de los créditos por ciclo, en el caso de las personas con discapacidad, es más lento debido a las adaptaciones que los estudiantes requieren en la malla curricular y el aprendizaje. En segundo lugar, los estudios de inglés requieren siempre un costo adicional que, para las personas con discapacidad, no es prioritario en todos los casos. Esto se debe a que, debido a los altos gastos en servicios de salud y rehabilitación, las personas con discapacidad son las que tienen más probabilidades de experimentar situaciones socioeconómicas adversas.

Otras razones mencionadas por las personas entrevistadas ${ }^{(12)}$ tienen relación con aspectos económicos, falta de vacantes y contactos. De igual manera, manifestaron que las principales barreras para estudiantes con discapacidad estaban basadas en el temor a no encontrar prácticas en el área de interés en Derecho y que no sean aceptados por la implementación de los ajustes razonables ${ }^{(13)}$. Resulta comprensible en un contexto en el que la legislación vigente no protege a los estudiantes con discapacidad de sus empleadores.

Por último, es importante resaltar que los estudiantes con discapacidad encuentran las barreras desde el momento en que acuden a una entrevista de postulación. Por ejemplo, una estudiante con discapacidad visual ${ }^{(14)}$ nos comentó que identificó un problema en relación a la expresión corporal, ya que para una persona sin discapacidad es fácil saber (por la mirada) cuando está dando una entrevista buena o no, y modular en consecuencia su comportamiento; en el caso de las personas con discapacidad visual, esto no ocurre así.

\subsection{Sobre las barreras en el ejercicio de las prácticas}

Existen dos grandes preocupaciones para los estudiantes con discapacidad al momento de realizar sus prácticas que configuran barreras: la falta de espacios accesibles, la falta de implementación de ajustes razonables por parte del empleador y la falta de comprensión por parte de sus jefes sobre cuestiones académicas. Sobre el primero, todas las personas entrevistadas ${ }^{(15)}$ manifestaron que su principal preocupación es que el ambiente de las prácticas no sean lugares accesibles. Por ejemplo, un entrevistado con discapacidad física(16) manifestó que antes de iniciar sus prácticas, tenía temor que su espacio de trabajo no sea adecuado para las labores que desempeñaría. No obstante, indicó que luego de su ingreso se instaló una rampa en la puerta y se acondicionó el baño a sus necesidades. A pesar de lo anterior, el entrevistado refirió que a la hora del refrigerio tenía que ser cargado por sus compañeros, pues el comedor se encontraba en el primer piso y el centro de prácticas no contaba con ascensor.

Los inconvenientes que atravesó el estudiante entrevistado responden a la desprotección del marco jurídico en el ejercicio de las prácticas de los estudiantes con discapacidad. Asimismo, al no existir una obligación legal de implementar ajustes razonables en los centros de prácticas, el empleador tiene el camino abierto para decidir si lo hace o no. Esto impide que la aplicación de los ajustes razonables sea vista como el ejercicio de un derecho, y la denegación de ella, como un acto discriminatorio, tal como lo señala la Ley General de la Persona con Discapacidad referente al derecho al trabajo. Además, el empleador, al no estar capacitado en el abordaje de la discapacidad, no siempre va a tomar las medidas más adecuadas para garantizar la accesibilidad del espacio, como ocurrió en el caso al optar por cargar todos los días al practicante con discapacidad. Incluso, estas medidas pueden ocasionar vulneraciones de derechos, como el de la

\footnotetext{
(9) Entrevistas a PCD 1-UNMSM, PCD 2-UNMSM, PCD 3-PUCP, PCD 4-PUCP, PCD 5-PUCP y PCD 6-PUCP.

(10) Entrevistas a PCD 1-UNMSM, PCD 2-UNMSM y PCD 3-PUCP.

(11) Entrevistas a PCD 1-UNMSM, PCD 2-UNMSM y PCD 3-PUCP.

(12) Entrevistas a PCD 1-UNMSM, PCD 2-UNMSM y PCD 4-PUCP.

(13) Entrevistas a PCD 1-UNMSM, PCD 2-UNMSM y PCD 4-PUCP.

(14) Entrevista a PCD 3-PUCP.

(15) Entrevistas a PCD 1-UNMSM, PCD 2-UNMSM, PCD 3-PUCP, PCD 4-PUCP, PCD 5-PUCP y PCD 6-PUCP.
} 
autonomía.

Además, algunos estudiantes con discapacidad(17) concuerdan que les genera un alto costo movilizarse hacia su centro de prácticas. Esto en la medida que el transporte público no es accesible. En esa línea, dos estudiantes con discapacidad $^{(18)}$ refieren que compatibilizar las horas de prácticas con las horas de estudio llega a generarles muchos dilemas. Sumado a esto, existen diversas críticas sobre la falta de comprensión por parte de los empleadores sobre temas académicos como el horario. Algunos empleadores no respetan el horario de clases de los estudiantes, lo que genera no solo que falten a la universidad, sino que las horas en los centros de formación se extiendan más de las treinta (30) horas semanales. Al respecto, según la información recogida en 2019 por la Oficina de Prácticas Preprofesionales y SECIGRA Derecho de la Pontificia Universidad Católica del Perú(19), el Estado prioriza el cumplimiento de las 30 horas de prácticas dentro de sus instituciones mientras que las empresas o entidades privadas no, ya que: (i) existe un amplio consenso entre los practicantes de las entidades públicas (74.2\%) que sus centros de prácticas respetan el horario de 30 horas semanales; (ii) en los estudios de abogados, el $32 \%$ de estudiantes entrevistados señaló que practica de 31 a 40 horas semanales; y (iii) en las entidades privadas el $26.2 \%$ de estudiantes señaló que practica de 31 a 40 horas semanales (OPPS, 2019).

Es innegable que existe un contexto de alta competitividad que lleva a que los estudiantes toleren, minimicen o avalen esta práctica. Los estudiantes saben que existe una idea de estándar de abogado exitoso, que busca ser el mejor, que prioriza siempre su trabajo, que se sobre-esfuerza, que no descansa hasta conseguir sus objetivos. Estos estereotipos, muy presentes en el círculo de abogados y estudiantes de Derecho, solo generan que los estudiantes no midan las consecuencias en su salud por el exceso de trabajo. Así, luego de terminar su carrera universitaria y ejercer su profesión conforme al estándar establecido, son propensos a formar la lista de abogados víctimas de la depresión, ansiedad, alcoholismo y abuso de drogas, suicidio, y otras afectaciones a su salud física y emocional. Este estándar normalizado de éxito puede afectar mucho más a los practicantes con discapacidad por el contexto de discriminación estructural.

\subsection{Sobre la inserción laboral posterior al ejercicio de las prácticas \\ Uno de los problemas vinculados a la realización de prácticas}

es el acceso al empleo luego de terminarlas. Sobre este tema, algunos estudiantes con discapacidad ${ }^{(20)}$ manifestaron que un problema es no encontrar puestos laborales en el área de interés que tienen en el Derecho, optando por puestos en entidades en el Estado que no necesariamente se ajustan a sus preferencias o especialización.

Sumado a ello, debe considerarse que la realización de las prácticas es un requisito previo para obtener el título profesional, en ese sentido, las personas con discapacidad que no puedan cumplir con la realización de prácticas preprofesionales o profesionales, no podrán insertarse laboralmente en centros que soliciten como requisito mínimo la obtención del título.

\section{Marco normativo de las prácticas en Perú con enfoque de discapacidad}

Si bien la Ley General de la Persona con Discapacidad no hace diferencia respecto al tipo de vínculo laboral que se requiere para que las personas con discapacidad puedan disfrutar de sus derechos, sí establece ciertos derechos que se restringen al ámbito laboral, tales como: la cuota de empleo; la bonificación de $15 \%$ en concurso público; y la implementación de los ajustes razonables (Ley 29973, 2012, artículo 3). Además de ello, los empleadores reciben un crédito por la realización de ajustes razonables dependiendo del número de trabajadores con discapacidad beneficiados.

Bajo estos parámetros, los practicantes con discapacidad se han visto impedidos de acceder a ciertos derechos. Sin embargo, el marco normativo ofrece algunas protecciones específicas. Algunas provienen de una interpretación extensiva, que cabe en el marco de los derechos humanos; en otros casos, por disposiciones reglamentarias que han incluido una perspectiva de

(16) Entrevista a PCD 1-UNMSM.

(17) Entrevista a PCD 2-UNMSM, PCD 3-PUCP, PCD 4-PUCP, PCD 5-PUCP y PCD 6-PUCP.

(18) Entrevista a PCD 1-UNMSM y PCD 2-UNMSM.

(19) La encuesta tuvo una muestra de 195 practicantes de la Facultad de Derecho, siendo 65 hombres y 130 mujeres. La muestra se divide en tres grupos: 122 practicantes en Estudios de Abogados, 31 practicantes en Entidades Públicas y 42 practicantes en Entidades Privadas. Por ello, la presente información no es representativa del Perú.

(20) Entrevistas a PCD 1-UNMSM y PCD 2-UNMSM. 
Difícil para unos, utópico para otros: la deficiente regulación de las prácticas formativas y su impacto negativo en las personas con discapacidad

Challenging for some, utopian for others: the poor regulation of training practices and its negative impact on people with disabilities

discapacidad.

4.1. Nuevos derechos en el acceso de las prácticas: cuota, ajustes en los procedimientos de selección y bonificación en los procesos públicos

La Ley sobre Modalidades Formativas Laborales establece que "la participación de las personas en las diversas modalidades formativas debe darse en condiciones de igualdad y sin discriminación alguna" (Ley 28518, 2005, artículo I.2). Consideramos que si bien es importante que el principio de igualdad y no discriminación sea transversal en la legislación y se manifieste de forma expresa en la legislación relativa a las modalidades formativas, esta no enfatiza las situaciones de discriminación en perjuicio de las personas con discapacidad. Lo cual es de suma importancia toda vez que este colectivo conforma un grupo históricamente invisibilizado que requiere de medidas afirmativas para su inclusión en la sociedad. Además, llama la atención que este artículo solo se encuentre en la norma relativa a las prácticas en el ámbito privado, y no en el ámbito público.

En esa línea, los practicantes con discapacidad no cuentan para la cuota de empleo en ninguno de los ámbitos pues no se les considera trabajadores. Por ello, es importante incorporar una medida intermedia que incentive a estos centros de prácticas a contar con practicantes con discapacidad sin perjudicar a los trabajadores. Piénsese, por ejemplo, en una empresa que quiera llenar toda su cuota de empleo con practicantes dejando de lado a los trabajadores, siendo estos últimos los que acarrean mayores costos por el reconocimiento pleno de sus derechos laborales. Ante ese panorama, proponemos que se establezca un tope máximo a la cuota de empleo: que del $5 \%$ y del $3 \%$ de la totalidad del personal, destinado a contratar trabajadores con discapacidad, se reserve un $1 \%$ para prácticas de personas con discapacidad. Sin duda, nuestra postura principal es que se reconozca la relación laboral de las prácticas para que gocen de los mismos derechos que los trabajadores. No obstante, en el camino para alcanzar dicho propósito es importante que se den medidas a favor de los practicantes.

Consideramos que las entidades públicas y los empleadores privados que convengan con estudiantes y egresados con discapacidad, deben ser consideradas como entidades que cumplen con la cuota laboral, según su ámbito, que conlleva a la deducción tributaria de la entidad establecida en el artículo 47 de la Ley General de la Persona con Discapacidad. De esa manera, abrimos la posibilidad de que las entidades públicas y las entidades privadas gocen de un beneficio en materia laboral, y aseguren la inclusión de los estudiantes con discapacidad en el espacio de las prácticas.

Sin perjuicio de ello, reconocemos que el problema de la falta de inclusión de los estudiantes con discapacidad no será solucionado únicamente con los incentivos de cuota o los incentivos tributarios, ya que dicho problema responde también a los altos niveles de exclusión en el sistema educativo escolar y superior. Incluso en el caso de familias que puedan pagar los altos costos de un centro educativo privado, enfrentan discursos y prácticas discriminatorias encubiertas en estos colegios que terminan en su no aceptación en la institución (Galicia, Bregaglio \& Constantino, 2015).

Las medidas antes descritas son necesarias para promover la inclusión de los estudiantes y egresados con discapacidad en las prácticas. Ello es importante no solo porque le permite a este colectivo acceder a un derecho que antes no encontraba protegido, sino que permitirá que estudiantes, o egresados, puedan cumplir -en un plazo más reducido de tiempo- con el requisito para titularse, e insertarse posteriormente en el mercado laboral.

Al respecto, es importante destacar que, según la Encuesta Nacional a Egresados Universitarios y Universidades del año 2014 , solo el $43,9 \%$ de egresados universitarios cuenta con título profesional para desempeñarse como profesional ante cualquier entidad (INEI, 2015, p. 97). Precisamente esto ocurre porque los egresados consideran que los requisitos para obtener la titulación son muy complicados. Esta realidad muestra lo complejo que pueden ser los requisitos exigidos para la titulación, lo cual promueve que muchos estudiantes desistan en la búsqueda del título universitario.

Por otro lado, otra necesidad para una inclusión verdadera tiene que ver con la realización de ajustes razonables en la etapa de selección. Los ajustes razonables, según la Convención sobre los Derechos de las Personas con Discapacidad, "son modificaciones y adaptaciones necesarias requeridas en un caso particular, para garantizar a las personas con discapacidad el goce o ejercicio, en igualdad de condiciones con las demás, de todos los derechos humanos y libertades fundamentales" (Convención sobre los Derechos de las Personas con Discapacidad, 2006, artículo 2). La normativa interna ha señalado el derecho a los ajustes razonables de los postulantes. En 
el ámbito privado rige los Lineamientos para el otorgamiento de ajustes razonables a las personas con discapacidad en el proceso de selección y en el lugar de trabajo, y los criterios para determinar una carga desproporcionada o indebida, aplicables en el sector privado (Resolución Ministerial 171-2019-TR, 2019).

En el ámbito público rige de forma general el artículo 52 del Reglamento de la Ley 29973. Asimismo, los Lineamientos para el otorgamiento de ajustes razonables a las personas con discapacidad en el proceso de selección que realicen las entidades del sector público (Resolución de Presidencia Ejecutiva 140-2019-SERVIR-PE, 2019). Además de los Lineamientos para el otorgamiento de ajustes razonables a las personas con discapacidad en el lugar de trabajo y los criterios para determinar una carga desproporcionada o indebida, aplicables en el Sector Público (Decreto Supremo 001-2020-TR, 2020). A pesar de esta amplitud de normas en materia laboral, no se ha desarrollado un marco jurídico similar para los practicantes en esta materia. Cabe resaltar que los ajustes razonables tienen un respaldo en el mandato de no discriminación, y podrían estar orientados a buscar un real y efectivo ejercicio de las prácticas formativas de los estudiantes y egresados con discapacidad.

Finalmente, en el ámbito de la selección, debe pensarse también en la bonificación en los concursos públicos. El Reglamento que regula las modalidades formativas de servicios en el sector público señala que "el acceso a prácticas preprofesionales y profesionales en entidades del sector público se realiza obligatoriamente mediante concurso público" (Decreto Supremo 083-2019-PCM, 2019, artículo 18). Si bien este artículo no hace explícito el derecho a la bonificación de las personas con discapacidad en los concursos públicos de méritos, ello está reconocido en el artículo 48 de la Ley General de la Persona con Discapacidad.

Es importante señalar que la norma no restringe su ámbito de aplicación a un tipo de relación laboral. Por el contrario, establece que la bonificación y los ajustes en los procedimientos de selección y evaluación se aplican a los concursos independientemente del régimen laboral. En esa misma línea se ha pronunciado el Ministerio de Trabajo y Promoción del Empleo en el Informe Técnico 113-2018MTPE/2/15.1 (Ministerio de Trabajo y Promoción del Empleo, 2018).

La Ley General de la Persona con Discapacidad establece ciertos requisitos para la obtención de la bonificación en los concursos convocados en el sector público: «(i) que el concurso sea convocado por una entidad pública; (ii) que cumpla con los requisitos para el cargo; y (iii) que la persona con discapacidad haya alcanzado un puntaje aprobatorio» (Ley 29973, 2012, artículo 48). En tanto, se cumplirían con las exigencias del caso si: (i) fuesen convocatorias públicas a cargo de la Autoridad Nacional del Servicio Civil, (ii) se exige a las entidades que determinen los requisitos académicos (referidos al nivel, ciclo de estudios u otros) y (iii) no se establezca algún requisito que configure discriminación directa o indirecta.

Si bien esta interpretación que realizamos es positiva para los derechos de las personas con discapacidad debió hacerse explícito el derecho de este colectivo de acceder a la bonificación y los ajustes en los procedimientos de selección y evaluación. Ello en razón de que las autoridades que garanticen este derecho no tengan dudas de que estas medidas son aplicables en los casos de prácticas preprofesionales y profesionales.

\subsection{Ajustes razonables en la ejecución de las prácticas}

Con el objeto de un real y efectivo ejercicio en las prácticas por parte de los estudiantes y egresados con discapacidad proponemos que se extiendan los ajustes razonables a este colectivo. Los ajustes razonables tienen un respaldo en el mandato de no discriminación y el principio de igualdad en cuanto se da un trato diferente a las personas con discapacidad en razón de sus diferencias. Nótese que aplicar el principio de igualdad de manera formal implicaría un acto de discriminación dada las condiciones reales de la sociedad y las barreras en general. Bajo estos parámetros, la implementación de ajustes razonables no sería una forma de discriminación hacia los estudiantes y egresados sin discapacidad.

En líneas generales, los objetivos de los ajustes razonables aplicado en las prácticas serían dos. En primer lugar, que el empleador realice adaptaciones en el Centro de Prácticas satisfaciendo las necesidades de cada practicante con discapacidad. En segundo lugar, que el empleador facilite la participación activa de los practicantes con discapacidad en un mismo grado que los demás practicantes y trabajadores.

No obstante, podría el empleador alegar carga indebida o desproporcionada. Ante ello, se debe proceder a realizar un análisis sobre la razonabilidad de los ajustes razonables. Primero, identificar el costo específico del ajuste razonable. Es decir, si va ser un costo 
fácil de calcular o, por el contrario, un costo indeterminado por las modificaciones en la rutina de las prácticas, sea de horario o de actividades específicas. Segundo, identificar el costo de las repercusiones en el entorno laboral si se decide aplicar el ajuste. Tercero, poner en una balanza el costo específico, el costo de las repercusiones y los beneficios presentes y futuros que se crearían a favor del Centro de Prácticas. Entonces, el empleador podrá argumentar una carga indebida solo cuando el practicante con discapacidad no genere beneficios ni tampoco un beneficio social que supere los costos (Constantino \& Galicia, 2015, p. 275).

Dicho lo anterior, evidentemente, los ajustes razonables no pueden quedarse únicamente en el ámbito del proceso de selección, sino que deben expandirse a toda la ejecución de la modalidad formativa. Como se ha señalado, la Ley General de la Persona con Discapacidad no establece diferencias por forma contractual. Por ello, debería entenderse que sí corresponde aplicarse a las prácticas preprofesionales y profesionales.

De manera más precisa, en el sector privado, la Resolución Ministerial 171-2019-TR incluye a las prácticas preprofesionales y profesionales en el diseño de ajustes razonables. Sin embargo, no podemos decir lo mismo del sector público, ya que en la Resolución de Presidencia Ejecutiva 140-2019-SERVIR-PE y en el Reglamento de la Ley del Servicio Civil de Graduandos SECIGRA Derecho no se incluyó dicho diseño.

En esa línea, la normativa del SECIGRA por un corto tiempo reconoció los ajustes razonables a los secigristas con discapacidad en la quinta disposición complementaria final del derogado Reglamento de la Ley del Servicio Civil de Graduando, Decreto Supremo 001-2018-JUS. Sin embargo, mediante el Decreto Supremo 001-2020-TR se dispuso derogar el Decreto Supremo 001-2018-JUS y retornar la vigencia al Decreto Supremo 009-2014-JUS, el cual no tiene enfoque de discapacidad. Cabe mencionar que las personas con discapacidad que practican en el sector público y privado se encuentran en igual desprotección.

Como una forma de facilitar la inclusión de practicantes con discapacidad, se podría habilitar la modalidad de teletrabajo o práctica remota, adaptado a practicantes con discapacidad. Sin embargo, esta no es una medida que se haya incluido en la regulación de las modalidades formativas. Por ello, consideramos necesario que se incluya la modalidad de teletrabajo o práctica remota en las prácticas preprofesionales y profesionales. Ello resolvería las barreras de accesibilidad arquitectónica que son causa de la denegación de prácticas para estudiantes y egresados con discapacidad en muchos casos y fomentaría la inclusión de las personas con discapacidad en la formación práctica. Si bien, cabrían dentro de la implementación de los ajustes razonables consideramos que debe hacerse expresa su intención por parte de ellos para promover su uso y publicitar esta medida como otra alternativa válida en favor de los practicantes con discapacidad. Así, la regulación de las teleprácticas o práctica remota tendrían que estar acompañada por el seguimiento y la supervisión del Ministerio de Trabajo y Promoción del Empleo, a fin de no desvirtuar esta modalidad y garantizar su carácter formativo.

De esta manera, se observa la existencia de un vacío legal para los estudiantes con discapacidad, quienes no podrán obtener el título hasta no superar la barrera social en el acceso y ejercicio de las prácticas. En la medida en que no existe una norma específica que regule la situación de los practicantes con discapacidad, este colectivo se encuentra en una situación de alta vulnerabilidad respecto del acceso y ejercicio de prácticas preprofesionales y profesionales.

\section{Conclusiones}

Las prácticas preprofesionales y profesionales constituyen una parte esencial en la formación académica de los estudiantes. Sin embargo, los estudiantes con discapacidad se enfrentan a diversas barreras. Principalmente las de accesibilidad (en la estructura arquitectónica, en el espacio específico donde llevan a cabo sus prácticas, entre otras) e implementación de ajustes razonables durante la búsqueda, la postulación y ejercicio de las prácticas. En ese sentido, las dos grandes preocupaciones de los estudiantes con discapacidad al momento de realizar sus prácticas son la falta de ajustes razonables por parte de los empleadores y la falta de comprensión por parte de sus jefes o jefas sobre cuestiones académicas. Por ello, el principal problema futuro de los estudiantes que realizaron prácticas es el acceso a puestos laborales en el área de interés que tienen en el Derecho; caso contrario los estudiantes que no realizaron prácticas es no poder insertarse laboralmente en centros que soliciten como requisito mínimo la obtención del título.

Por otro lado, la regulación actual en materia de prácticas preprofesionales y profesionales no plantea un reconocimiento de estas como trabajo. Por el contrario, hace 
una tajante desvinculación a nivel normativo. Ello genera una desprotección general que afecta de manera especial a los practicantes con discapacidad respecto de la búsqueda, el acceso y ejercicio de las prácticas, aun siendo una población en situación de alta vulnerabilidad. Por tanto, las medidas que podrían cambiar el vacío normativo actual corresponden a: hacer explícito que los centros de prácticas estén obligados a implementar y cubrir económicamente los ajustes razonables a los practicantes con discapacidad. Siendo indispensable lo anterior para alcanzar la igualdad de condiciones. Asimismo, implementar una cuota de práctica que se conecte con la cuota laboral en beneficio de las entidades que lo apliquen; entre otras. El fin último es poder conseguir la real y efectiva igualdad de las personas con discapacidad en estos espacios. Para ello, se requiere la intervención del Estado, la sociedad civil y, principalmente, la participación de los actores directos involucrados: las personas con discapacidad.

\section{Referencias bibliográficas}

Arce, E. (2007). Naturaleza Jurídica de las modalidades formativas laborales en la empresa. Foro Jurídico (7), 170-178. http://revistas. pucp.edu.pe/index.php/forojuridico/article/view/18470/18710

Consejo Nacional para la Integración de la Persona con Discapacidad (CONADIS). (2018). Resultados de fiscalizaciones a universidades públicas y privadas en Lima Metropolitana. https://www.conadisperu. gob.pe/notas-informativas/63994

Constantino, R. A. \& Galicia, S. (2015). La configuración de los ajustes razonables en el ámbito laboral peruano: definiciones, omisiones y propuestas. En P. Urteaga \& A. Verona (eds.), Anuario de Investigación del CICAJ 2012-2014, Las instituciones jurídicas en debate (pp. 261-288). CICAJ. http://repositoriocdpd.net:8080/ bitstream/handle/123456789/1014/Art_ConstantinoCaychoRA_ AjustesRazonablesLaboral_2015.pdf?sequence=2

Convención sobre los Derechos de las Personas con Discapacidad (2006)

Decreto Ley 26113 (1992). Aprueban normas relativas al Servicio Civil de Graduandos SECIGRA Derecho. Diario Oficial El Peruano (30 de diciembre).

Decreto Legislativo 1401 (2018). Decreto Legislativo que aprueba el régimen especial que regula las modalidades formativas de servicios en el sector público. Diario Oficial El Peruano (11 de septiembre).

Decreto Supremo 003-97-TR (1997). Texto Único Ordenado del Decreto Legislativo 728, Ley de Productividad y Competitividad Laboral. Diario Oficial El Peruano (21 de marzo).

Decreto Supremo 007-2005-TR (2005). Reglamento de la Ley 28518 "Ley sobre Modalidades Formativas Laborales", Ministerio de Trabajo y Promoción de Empleo. Diario Oficial El Peruano (19 de septiembre ).

Decreto Supremo 003-2008-TR (2008). Dictan medidas sobre jornadas máximas de modalidades formativas reguladas por la Ley 28518 solo de las prácticas preprofesionales de Derecho y de internado en Ciencias de la Salud. Diario Oficial El Peruano (20 de mayo). Decreto Supremo 002-2014 (2014). Reglamento de la Ley 29973, Ley General de la Persona con Discapacidad. Diario Oficial EI Peruano (7 de abril).

Decreto Supremo 009-2014-JUS (2014). Reglamento de la Ley del Servicio Civil de Graduandos. Diario Oficial El Peruano (31 de octubre).

Decreto Supremo 001-2018-JUS (2018). Reglamento del Decreto Ley 26113, modificado por la Ley 27687 - Ley del Servicio Civil de Graduando, SECIGRA Derecho. Diario Oficial EI Peruano (27 de enero).

Decreto Supremo 083-2019-PCM (2019). Decreto Supremo que aprueba el Reglamento del Decreto Legislativo 1401, Decreto Legislativo que aprueba el Régimen Especial que regula las modalidades formativas de servicios en el Sector Público. Diario Oficial El Peruano (24 de abril).

Decreto Supremo 001-2020-TR (2020). Lineamientos para el otorgamiento de ajustes razonables a las personas con discapacidad en el lugar de trabajo y los criterios para determinar una carga desproporcionada o indebida, aplicables en el Sector Público. Diario Oficial El Peruano (3 de enero).

Decreto Supremo 001-2020-JUS (2020). Decreto Supremo que deroga el Decreto Supremo 0012018-JUS, que aprueba el Reglamento del Decreto Ley 26113, modificado por la Ley 27687 - Ley del Servicio Civil de Graduandos SECIGRA Derecho. Diario Oficial EI Peruano (9 de enero).

Galicia, S., Bregaglio, R. \& Constantino, R. (2015). Un inocente editorial. Respuesta al Editorial de El Comercio del 28 de diciembre sobre el efecto negativo de las cuotas de empleo para las personas con discapacidad. Enfoque Derecho. https://www. enfoquederecho.com/2015/12/28/una-inocenteeditorial-respuesta-a-la-editorial-de-el-comerciodel-28-de-diciembre-sobre-el-efecto-negativode-las-cuotas-de-empleo-para-las-personas-condiscapacidad/

Informe provisional - Informe núm.304 (1996). Caso núm. 1796 (Perú) Organización Internacional del Trabajo. Disponible en: https://www.ilo.org/dyn/ normlex/es/f?p=NORMLEXPUB:50002:0::NO: :P50002_COMPLAINT_TEXT_ID:2903259

Informe Técnico N¹13-2018-MTPE/2/15.1 (2018). Respuesta a la solicitud de opinión técnica de la Clínica Jurídica en Discapacidad de la Pontificia Universidad Católica del Perú (5 de noviembre).

Instituto Nacional de Estadística e Informática. (2015). Encuesta Nacional a Egresados Universitarios y Universidades, 2014. Principales resultados. INEI. https://www.inei.gob.pe/media/ MenuRecursivo/publicaciones_digitales/Est/ 


\section{Lib1298/Libro.pdf}

Instituto Nacional de Estadística e Informática. (2018). Censos Nacionales 2017: XII de Población y VII de Vivienda y III de Comunidades Indígenas. INEI. https://www.inei.gob.pe/media/ MenuRecursivo/publicaciones_digitales/Est/ Lib1539/libro.pdf

Ley 28518 (2005). Ley sobre Modalidades Formativas Laborales (24 de mayo).

Ley 29973 (2012). Ley General de la Personas con Discapacidad. Diario Oficial El Peruano (13 de diciembre).

Ley 30220 (2014). Ley Universitaria. Diario Oficial El Peruano (9 de julio).

Ministerio de Educación. (2017). Atención de personas con discapacidad en la educación superior universitaria en el año 2017. MINEDU. http://www.minedu.gob.pe/reforma-universitaria/ pdf/infografia_discapacidad.pdf

Neves, J. (2012). Introducción al Derecho del Trabajo (2. ${ }^{a}$ ed.). Pontificia Universidad Católica del Perú. http://biblioteca. cejamericas.org/bitstream/handle/2015/1134/ introduccionalderechotrabajoperu. pdf?sequence $=1 \&$ is Allowed $=y$

Oficina de Prácticas Preprofesionales y SECIGRA Derecho (2019). Resultados Ranking 2019 [infografía]. http://facultad.pucp.edu.pe/ derecho/oficina-practicas/wp-content/uploads/2020/08/ResultadosRnaking-2019-2.pdf

Resolución de Presidencia Ejecutiva N¹40-2019-SERVIR-PE (2019). Lineamientos para el otorgamiento de ajustes razonables a las personas con discapacidad en el proceso de selección que realicen las entidades del sector público. Diario Oficial El Peruano (18 de octubre).

Resolución Ministerial N¹71-2019-TR (2019). Lineamientos para el otorgamiento de ajustes razonables a las personas con discapacidad en el proceso de selección y en el lugar de trabajo, y los criterios para determinar una carga desproporcionada o indebida, aplicables en el sector privado. Diario Oficial El Peruano (3 de julio).

Superintendencia Nacional de Educación Superior Universitaria. (2020). Estadísticas, Estado de Licenciamiento de las Universidades. https://www.sunedu.gob.pe/avances-licenciamiento/

Toyama, J. (2008). La relación laboral: constitución y desarrollo. En Derecho Individual del Trabajo. (p. 92-127). Gaceta Jurídica. https://www.trabajo.gob.pe/archivos/file/inspectores/concurso/2013/ lectura4_inspectores_efp.pdf

Vidal, M. (2009). Los derechos laborales en las constituciones peruanas. Revista Foro Jurídico (9), p 167-176.http://revistas.pucp.edu. pe/index.phqqqqqp/forojuridico/article/view/18528/18768 